\title{
First report of Nigrospora sphaerica causing leaf spot of date palm in Pakistan
}

\author{
Muhammad Waqar Alam ${ }^{1}$ - Abdul Rehman ${ }^{2}$. Shahbaz Ahmad ${ }^{1}$. Mubeen Sarwar ${ }^{1}$. Aamir Nawaz ${ }^{3}$. \\ Samiya Mahmood Khan ${ }^{4}$. Sajid Ali $^{3} \cdot$ Sidra Aslam ${ }^{5}$. Abdul Mannan ${ }^{1}$
}

Received: 3 November 2018 / Accepted: 3 July 2019 / Published online: 12 July 2019

(C) Società Italiana di Patologia Vegetale (S.I.Pa.V.) 2019

Keywords Nigrospora sphaerica $\cdot$ Leaf spot $\cdot$ Pathogenicity

Date palm (Phoenix dactylifera $\mathrm{L}$.) is one of the most cultivated fruit trees around the world. Pakistan is the 6th largest producer of dates (Mangan et al. 2016). During November 2017, leaf spot symptoms were observed in different date palm orchards. Symptoms included yellow to brown, semicircular to irregular spots ( $3 \mathrm{~mm}$ diameter), which gradually enlarged up to $8 \mathrm{~mm}$ diameter and coalesced. Symptomatic tissues of infected leaves were cut into small pieces, surface sterilized in $75 \%$ ethanol for $30 \mathrm{~s}$, rinsed three times in sterile distilled water, and cultured onto potato dextrose agar (PDA) for $5-7$ days at $25{ }^{\circ} \mathrm{C}$. A purified culture of the isolated pathogen (PD20181) was stored at the Fungal Culture Collection Centre, Department of Plant Pathology, University of Agriculture, Faisalabad. The fungus produced single celled, black, spherical to subspherical conidia (10 to $14 \times 18$ to $20 \mu \mathrm{m}$ ), borne on a hyaline vesicle at the tip of each conidiophore. Morphologically, the fungus was identified as Nigrospora sphaerica (Sacc.) Mason (Mason 1927; Wang et al. 2017). Identification was confirmed by amplifying and sequencing the ITS region and translation elongation factor 1alpha $(T E F 1-\alpha)$ using primers ITS1/ITS4 (White et al. 1990) and EF1-728F (Carbone and Kohn 1999), respectively. BLAST

Muhammad Waqar Alam

waqaralam2009@gmail.com

1 Institute of Agricultural Sciences, University of the Punjab, Lahore, Pakistan

2 Department of Plant Pathology, University of Agriculture, Faisalabad, Pakistan

3 Department of Horticulture, Faculty of Agricultural Sciences and Technology, Bahauddin Zakariya University, Multan, Pakistan

4 Department of Plant Pathology, Faculty of Agricultural Sciences and Technology, Bahauddin Zakariya University, Multan, Pakistan

5 Department of Ecology, College of Life Sciences, Beijing Normal University, Beijing, China analysis of GenBank Accession Nos. MH815137 and MK875828 showed 99 and 100\% identity with N. sphaerica strains (KX986034 and KY019414) from China. Pathogenicity was verified on 10 detached, surface-sterilized, healthy leaves (cv. Aseel). Leaves were wounded and inoculated with a mycelial plug of $0.5 \mathrm{~cm}$. Leaves inoculated with sterile PDA plug served as negative control. Leaves were placed in a moist chamber at $25{ }^{\circ} \mathrm{C}$ and $80 \% \mathrm{RH}$. Twelve days post inoculation, inoculated leaves had symptoms similar to those originally observed on affected trees; control remained asymptomatic. The morphological characteristics of the fungi reisolated from inoculated leaves were the same as of original isolates, fulfilling Koch's postulates. Nigrospora sphaerica has been reported to cause leaf spot of Kinnow mandarin in Pakistan (Alam et al. 2017). To our knowledge, this is the first report of leaf spot caused by $N$. sphaerica on date palm in Pakistan.

\section{References}

Alam MW, Rehman A, Gleason ML, Riaz K, Saira M, Aslam S, Rosli R, Muhammad S (2017) First report of Nigrospora spaherica causing leaf spot of Kinnow mandarin in Pakistan. J Plant Pathol 107:295

Carbone I, Kohn LM (1999) A method for designing sets for speciation studies in filamentous ascomycetes. Mycologia 91:553-556.

Mangan T, Abdul SJ, Mehar NR, Muhammad IK, Abdul GK (2016) Profit earned by date palm farmers and contractors in district Khairpur, Sindh, Pakistan. Sci Int 28:775-2779

Mason S.C. (1927). Date culture in Egypt and the Sudan. USDA bulletin no. 1457 , Washington, DC, pp. 72

Wang M, Liu F, Crous PW, Cai L (2017) Phylogenetic reassessment of Nigrospora: ubiquitous endophytes, plant and human pathogens. Persoonia 39:118-142

White TJ, Bruns TD, Taylor JW (1990) Amplification and direct sequencing of fungal ribosomal RNA genes for phylogenetics. In: Innis MA, Gelfand DH, Sninsky JJ, White TJ (eds) PCR protocols: a guide to methods and applications. Academic Press, San Diego, pp 315-322

Publisher's note Springer Nature remains neutral with regard to jurisdictional claims in published maps and institutional affiliations. 